\title{
The UREThRAL stricture score: A novel method for describing anterior urethral strictures
}

\author{
Lucas R. Wiegand, MD; Steven B. Brandes, MD \\ Division of Urology, Washington University in St. Louis, St. Louis, Missouri
}

See related article on page 265 .

Cite as: Can Urol Assoc J 2012;6(4)260-4. http://dx.doi.org/10.5489/cuaj.12048

\section{Abstract:}

Background: Urethral stricture description is not standardized. This makes surgical decision-making less reproducible and increases the difficulty of objectively analyzing urethroplasty literature. We developed a standardized system, the UREThRAL stricture score (USS), to quantify the characteristics of anterior urethral stricture disease based on preoperative imaging and intraoperative findings. Methods: To develop the USS, we retrospectively analyzed 95 consecutive patients with urethral strictures who underwent open urethroplasty by a single surgeon (SBB) at Barnes-Jewish Hospital from 2009 to 2011. The USS is a numerical score based on five components of anterior urethral stricture disease that help dictate operative decision-making: (1) (UR)ethral stricture (E)tiology; (2) (T) otal number of strictures; (3) (R)etention (luminal obliteration); (4) (A)natomic location; and (5) (L)ength. Stricture management was categorized by increasing surgical complexity: excision/primary anastomosis (EPA), buccal mucosal graft urethroplasty (BMG), augmented anastomotic urethroplasty (AAU), flap urethroplasty, and a combination of flaps and/or grafts. Multinomial logistic regression analysis was used to compare USS to surgical complexity.

Results: The mean USS for EPA, BMG, AAU, flap, and combination flaps/grafts was 5.78, 8.82, 9.23, 11.01, and 14.97, respectively. Increasing USS was significantly associated with surgical complexity $(p<0.0001)$.

Interpretation: The USS describes the essential factors in determining surgical treatment selection for urethral stricture disease. The USS is a concise, easily applicable system that delineates the clinically significant features of urethral strictures. Valuable comparison of anterior urethral stricture treatments in clinical practice and in the urological literature could be facilitated by using this novel UREThRAL stricture score.

\section{Introduction}

Disease scoring systems are a useful clinical decision-making tool in all areas of medicine. The creation of a scoring system in liver disease has helped to stratify patients for such difficult decisions as who will receive transplants. ${ }^{1}$ Scoring systems are also used in urologic surgery to predict outcomes after surgery for prostate cancer ${ }^{2}$ or to describe the complexity of renal masses. ${ }^{3}$ To our knowledge, there are no scoring systems for anterior urethral stricture disease to help in its qualitative description or guide clinical decision-making.

Urethral stricture disease affects about 300 per 100000 men. ${ }^{4}$ The decision to use a specific reconstructive technique depends upon surgeon preference, as well as many other factors, such as length, location and etiology of stricture. Generally, the least complex procedure necessary that gives durable results is preferred.

The pre- and intraoperative decision-making process is complex. There is scant prospective literature to support one procedure over another. Also, because there is no objective scoring system to describe urethral strictures, comparing results is difficult. Outcomes of complex repairs are also difficult to interpret without an objective measure of the characteristics of the strictures being repaired. With the creation of a numeric scoring system to describe the complexity of anterior urethral strictures, we hope to enable the comparison of surgical techniques across institutions and surgeons, while also offering a method to help facilitate surgical decision-making. Larger series from other institutions will obviously be needed to validate the USS.

\section{Methods}

All patients undergoing open urethroplasty by a single surgeon (SBB) at Barnes-Jewish Hospital were offered the opportunity to participate in a prospectively-collected, institutional review board-approved database. When we received patient consent, we created a database and populated it with patient 
demographics, data regarding the patients' strictures and the method of surgical treatment. Patients with prior optical urethrotomy were included in the study. Using this database to develop the UREThRAL stricture score (USS), we excluded all patients who had posterior strictures or who had a prior open urethroplasty, a known risk factor predictive of failure. ${ }^{5}$ Any patient who did not have complete data regarding the type of surgery or stricture characteristics was also excluded. To develop a scoring system that could be easily calculated and memorized, only five key factors were selected for inclusion. Admittedly, there are many potential factors that influence stricture complexity, but their inclusion would make the USS overly cumbersome and difficult to calculate.

These patients' stricture data were then coded into a Microsoft Excel (Redmond, WA) spreadsheet. Each data point from the stricture score was quantified and summed according to the proposed USS (Table 1). The type and complexity of each particular patient's surgical procedure was also coded according to the complexity of the operation (Table 2). Ranking order as to level of complexity was determined based on the senior author's surgical experience with over 500 urethroplasties. After compiling all of the data, multinomial logistic regression analysis was performed to determine if our USS was associated with complexity of surgery (SAS, Cary, NC).

\section{Results}

Between 2009 and 2011, we identified 115 patients; of these, 95 had anterior urethral strictures and met our inclusion criteria and had complete stricture data. The overall mean USS was $9.1 \pm 0.41$. Of the 95 patients, 29 underwent excision and primary anastomosis (EPA), 29 underwent buccal mucosal graft (BMG), 14 underwent augmented anastomotic urethroplasty $(\mathrm{AAU}), 8$ underwent penile fasciocutaneous flaps and 15 underwent a combination of flaps and/or grafts.
Mean USS increased with increasing surgical complexity (Table 3, Table 4). Mulltinomial logistic regression analysis confirmed that the USS was significantly associated with the level of complexity of surgery $(p<0.001)$. Thus, a higher USS is correlated with a more complex surgery.

\section{Discussion}

The USS was comprised of (UR)ethral stricture (E)tiology, (T) otal number of strictures, (R)etention (luminal obliteration vs. non-obliterative), (A)natomic location, and (L)ength. The purpose of the proposed anterior urethral scoring system was to provide a common language for reconstructive urologists to use when describing these strictures. The use of this common scoring system will hopefully allow for easier comparison between different advances in surgical technique, as well as for potential development of prognositic nomograms.

Complexity of surgery and urethral stricture recurrence are known to be affected by many variables, including body-mass index, ${ }^{6}$ smoking, prior endoscopic urethrotomy, and prior urethroplasty. ${ }^{5}$ As we were trying to develop a descriptive scoring system, we did not include these variables. These variables are certainly important and will likely need to be included in any nomogram that is developed to help determine stricture recurrence risk, along with the USS. While Devine and colleagues ${ }^{7}$ described a grading scale for spongiofibrosis and Jordan and colleagues ${ }^{8}$ recommended treatments based on this system, it was not our routine practice to objectively assess degree of spongiofibrosis, so data were not reliably available. Moreover, we know of no published reliable and reproducible preoperative imaging technique for quantifying spongiofibrosis. It was our routine to only send corpus spongiosum for pathologic analysis for anastomotic urethroplasties.

Those variables that we did include are described below (Table 1). There are only five components to the USS, as

\begin{tabular}{|c|c|c|}
\hline Component & Score & Description \\
\hline URethral stricture etiology & $\begin{array}{l}1=\text { traumatic, } \text { idiopathic, or iatrogenic } \\
2=\text { inflammatory or hypospadias }\end{array}$ & $\begin{array}{l}\text { Inflammatory or hypospadias-related strictures } \\
\text { are more likely to recur and usually require more } \\
\text { extensive reconstruction }\end{array}$ \\
\hline Total number of strictures & $1=$ point per stricture & $\begin{array}{l}\text { More than one stricture, especially when not close } \\
\text { together, is more difficult to treat }\end{array}$ \\
\hline Retention & $\begin{array}{l}1=\text { patent urethra } \\
2=\text { obliterated or near obliterated }\end{array}$ & $\begin{array}{l}\text { Represents the quality of the urethral plate and } \\
\text { whether there is a suitable site for a grafting } \\
\text { procedure }\end{array}$ \\
\hline Anatomic location & $\begin{aligned} 1 & =\text { bulbar urethra } \\
2 & =\text { penile urethra (including meatus and fossa) } \\
3 & =\text { panurethral or both bulbar and penile urethra } \\
& \quad \text { are involved }\end{aligned}$ & $\begin{array}{l}\text { Panurethral } \geq 1 / 2 \text { of the anterior urethra. Penile } \\
\text { urethral strictures usually require more difficult } \\
\text { reconstruction }\end{array}$ \\
\hline Length & 1 point per $\mathrm{cm}$ of length (to the nearest $0.1 \mathrm{~cm}$ ) & $\begin{array}{l}\text { Longer strictures are usually more difficult to treat, } \\
\text { especially as anastomotic reconstructions become } \\
\text { impractical. Length estimated by imaging and } \\
\text { confirmed intraoperatively }\end{array}$ \\
\hline
\end{tabular}


Wiegand and Brandes

\begin{tabular}{lc}
\hline $\begin{array}{l}\text { Table 2. Coding the type and complexity of each surgical } \\
\text { procedure }\end{array}$ & Level assigned \\
\hline Reconstruction & 1 \\
\hline Excision and primary anastomosis & 2 \\
Buccal mucosal or skin graft urethroplasty & 3 \\
Augmented anastomotic urethroplasty & 4 \\
Penile fasciocutaneous flap urethroplasty & 5 \\
\hline Combination of flaps and/or grafts & \\
\hline
\end{tabular}

we sought to develop a scoring system that could easily be calculated and memorized. To include all the factors that influence stricture complexity would have made the USS cumbersome and difficult to calculate. The inspiration for developing the USS was the RENAL nephrometry score for describing kidney tumor complexity, as detailed by Kutikov and Uzzo. ${ }^{3}$ The RENAL score's simplicity and limited number of components made it rapidly accepted and commonly used in many centres across the United States. The RENAL score was based on the subjective surgical experience of the senior author and only later was validated as an effective tool by other surgeons and other centres. It is our hope that the USS will also be subsequently tested for its validity by others.

\section{(UR)ethral stricture (E)tiology}

Stricture etiology is known to have an effect on complexity of surgery, as well as outcome. Men with lichen sclerosus et atrophicus (LSA) are much more likely to have penile urethral strictures, which most definitely increases the difficulty of surgical repair. Also, Levine and colleagues ${ }^{9}$ showed that patients undergoing urethroplasty for LSA-related strictures were more likely to develop recurrence than those patients without (5/13, $38 \%$ for LSA vs. $3 / 40,7 \%$ for non-LSA). Moreover, Andrich and colleagues ${ }^{10}$ also showed that LSA increases surgical complexity and the risk for stricture recurrence. Similarly, we included a higher score for those adult patients with hypospadias, either presenting for initial repair or secondary procedures. These patients have also been shown to require more complex and challenging procedures. ${ }^{11}$

\section{(T)otal number of strictures}

While there is no literature to support the inclusion of this criterion for open reconstruction, it has been shown to be a risk for recurrence after endoscopic urethrotomy. ${ }^{12}$ Regardless, we found that multiple strictures increase the complexity of repair. It is difficult to differentiate between one longer stricture and two shorter strictures that can be treated as one longer stricture, but by including length in the USS, this should be accounted for.

\begin{tabular}{lc}
\hline Table 3. UREThRAL stricture score & \\
\hline & $\mathbf{n = 9 5}$ \\
Mean & 9.10 \\
Standard error & 0.41 \\
Median & 8 \\
Mode & 5.5 \\
Standard deviation & 3.99 \\
Minimum & 4.5 \\
Maximum & 22 \\
\hline
\end{tabular}

\section{(R)etention (luminal obliteration vs. non-obliterative)}

The presence of luminal obliteration indicates that there is no suitable urethral plate for inlay or onlay procedures. With the exception of the short-segment obliterated bulbar urethra, the presence of urethral obliteration increases the complexity of the reconstruction. Guralnick and Webster ${ }^{13}$ and later Abouassaly and Angermeier ${ }^{14}$ describe an anastomotic urethroplasty with a ventral or dorsal graft/flap for stricture that are obliterative and long $(>1 \mathrm{~cm})$ to bridge the gap. The USS could anticipate the necessity of this more complex procedure preoperatively because it incorporates length of stricture and the presence of obliteration of the urethral lumen.

\section{(A)natomic location}

The location of the stricture is also important. It is obvious that more complex techniques are required to reconstruct penile strictures, as the corpus spongiosum is much thinner than in the bulb. The skin and subcutaneous tissue are very thin on the penis. There is also the concern for sexual dysfunction and chordee. For these reasons, penile and panurethral strictures are assigned a higher value. While most penile strictures will be related to iatrogenic causes, hypospadias or LSA, the inclusion of location is important to the USS because it is a descriptive scoring system.

\section{(L)ength}

Probably the most important factor, and weighted most heavily in the USS, is the length of the stricture. Longer strictures require more complex techniques for repair. Because

\begin{tabular}{lcc}
\hline \multicolumn{3}{l}{ Table 4. Type of UREThRAL stricture score } \\
\hline Treatment & Mean USS & \# of patients \\
\hline EPA & 5.78 & 29 \\
BMG & 8.82 & 29 \\
AAU & 9.23 & 14 \\
Flap & 11.01 & 8 \\
Combo flaps/grafts & 14.97 & 15 \\
\hline USS: UREThRAL stricture score; EPA: excision and primary anastomosis; \\
BMG: buccal mucosal graft urethroplasty; AAU: augmented anastomotic urethroplasty.
\end{tabular}




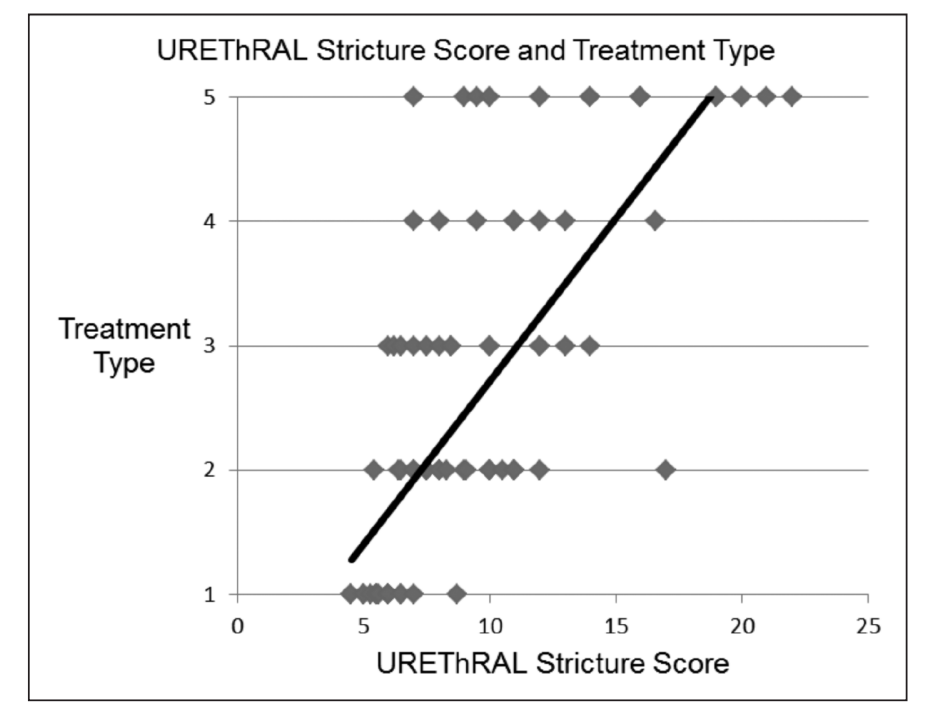

Fig. 1. 1: Excision and primary anastomosis; 2: Buccal mucosal graft urethroplasty; 3: Augmented anastomotic urethroplasty; 4: Flap; 5: Flaps +/Grafts. Solid line represents UREThRAL stricture score trend by treatment type.

the bulbar urethra is limited by length and elasticity, ${ }^{12}$ longer strictures will make the use EPA impossible. With a limited amount of substitution tissue, urethral reconstruction will require a combination of grafts and/or flaps as the stricture length increases, thus increasing the complexity of surgery. Also, stricture recurrence is known to be higher after endoscopic urethrotomy for longer strictures, ${ }^{15,16}$ as well as after open reconstruction. In a recent multivariate analysis of risk factors for stricture recurrence after urethroplasty, stricture length (especially $>4 \mathrm{~cm}$ ) predicted failure. ${ }^{6}$

By combining the scores for each of the above criteria, a single number can represent the complexity of a urethral stricture by objective means. A major limitation of the USS is that it represents a one-institution, one-surgeon description of approach to urethral reconstruction. As such, the level of surgical complexity represents the senior surgeon's bias and subjective experience with over 500 urethroplasties. Others may score the surgical complexity differently. However, the USS could still be used to augment decision-making, according to each surgeon's individual complexity level.

Other weakness of the USS are its retrospective design, that it excludes prior urethroplasty, and that it does not include other potential factors that may increase complexity, such as smoking or obesity. We did not include all factors associated with recurrence or complexity as we did not want the USS to become cumbersome or difficult to calculate. Our data are immature; clearly, large, multi-institutional studies with adequate follow-up are needed using the USS.

The next step will be to validate that USS correlates to complexity of repair at other institutions, as well as to document inter-observer reliability. From there, it can be used to describe stricture disease in comparing treatments. Standardizing and validating the description of anterior ure- thral strictures should allow for collaboration between institutions that will lead to higher level evidence for determining optimal treatments.

While there is no universally agreed upon measure of recurrence, ${ }^{17}$ the USS should help to stratify patients into complexity groups that will make future studies easier to perform by allowing easy comparison of urethral strictures. Also, as urethral reconstruction is a quality of life procedure, the development of patient-reported outcome measures ${ }^{4}$ will need to be correlated to an objective measure of the severity of the stricture disease.

\section{Conclusions}

Our proposed USS is a novel description of anterior urethral strictures. The five objective factors that comprise the score are essential to determining complexity and, potentially, the optimal reconstructive procedure. By using a universally understood and applicable method of describing anterior strictures, reconstructive urologists can improve the quality of literature for urethral stricture disease.

Acknowledgements: The authors would like to acknowledge Liu Yang for performing the statistical analysis included in this manuscript.

Competing interests: None declared.

This paper has been peer-reviewed.

\section{References}

1. Kamath PS, Kim WR. The Model for End Stage Liver Disease (MELD). Hepatology 2007;45:797-805. http://dx.doi.org/10.1002/hep.21563

2. Greene KL, Meng MV, Elkin EP, et al. Validation of the Kattan preoperative nomogram for prostate cancer recurrence using a community based cohort: results from cancer of the prostate strategic urological research endeavor (capsure). J Urol 2004;171:2255-9. http://dx.doi.org/10.1097/01. ju. 0000127733.01845 .57

3. Kutikov A, Uzzo R. The R.E.N.A.L. Nephrometry Score: A Comprehensive Standardized System for Quantitating Renal Tumor Size, Location and Depth. J Urol 2009;182:844-53. http://dx.doi. org/10.1016/i.juro.2009.05.035

4. Jackson MJ, Sciberras J, Mangera A, et al. Defining a Patient-Reported Outcome Measure for Urethral Stricture Surgery. Eur Urol 2011;60:60-8. http://dx.doi.org/10.1016/i.eururo.2011.03.003

5. Breyer BN, McAninch JW, Whitson JM, et al. Multivariate Analysis of Risk Factors for Long-Term Urethroplasty Outcome. J Urol 2010;183:613-7. http://dx.doi.org/10.1016/i.juro.2009.10.018

6. Breyer BN, McAninch JW, Whitson JM, et al. Effect of Obesity on Urethroplasty Outcome. Urology 2009;73:1352-6. http://dx.doi.org/10.1016/j.urology.2008.12.073

7. Devine CJ, Devine PD, Felderman TP, et al. Classification and standardization of urethral strictures. American Urological Association, 78th annual meeting (1983), abstract 325.

8. Jordan GH, Devine PC. Management of urethral stricture disease. Clin Plast Surg 1988;15:493-505.

9. Levine LA, Strom KH, Lux MM. Buccal Mucosa Graft Urethroplasty for Anterior Urethral Stricture Repair: Evaluation of the Impact of Stricture Location and Lichen Sclerosus on Surgical Outcome. I Urol 2007;178:2011-5. http://dx.doi.org/10.1016/i.juro.2007.07.034

10. Andrich DE, Greenwell TJ, Mundy AR. The problems of penile urethroplasty with particular reference to 2-stage reconstructions. J Urol 2003; 170:87-9. hittp://dx.doi.org/10.1097/01.ju.0000069721.20193.fd 
Wiegand and Brandes

11. Ching CB, Wood HM, Ross JH, et al. The Cleveland Clinic experience with adult hypospadias patients undergoing repair: their presentation and a new classification system. $\mathrm{Br} J$ Urol 2010;107:1142-6.

12. Koraitim MM. Gapometry and Anterior Urethrometry in the Repair of Posterior Urethral Defects. J Urol 2008;179:1879-81. http://dx.doi.org/10.1016/i.juro.2008.01.041

13. Guralnick ML, Webster GD. The Augmented Anastomotic Urethroplasty: Indications and Outcome in 29 Patients. J Urol 2001;165:1496-501. http://dx.doi.org/10.1016/S0022-5347(05)66335-5

14. Abouassaly R, Angermeier KW. Augmented Anastomotic Urethroplasty. J Urol 2007;177:2211-6. htrp:// dx.doi.org/10.1016/i.juro.2007.01.140

15. Albers P, Fichtner J, Bruhl P, et al. Long-term Results of Internal Urethrotomy. J Urol 1996;156:1611-4. http://dx.doi.org/10.1016/S0022-5347(01)65461-2
16. Steenkamp JW, Heyns CF, De Kock MLS. Internal Urethrotomy Versus Dilation as Treatment for Male Urethral Stricrtures: A Prospective, Randomized Comparison. J Urol 1997;157:96-101. http://dx.doi. org/10.1016/S0022-5347(01)65296-0

17. Meeks JJ, Erickson BA, Granieri MA, et al. Stricture Recurrence After Urethroplasty: A Systematic Review. J Urol 2009;182:1266-70. http://dx.doi.org/10.1016/i.juro.2009.06.027

Correspondence: Dr. Steven B. Brandes, Washington University School of Medicine, 4960 Children's Place, Box 8242, St. Louis, M0 63110; fax: 314-367-5016; brandess@wudosis.wust.edu 